\title{
Unraveling the Identity of Gastric Cardiac Cancer \\ Unraveling the Identity of Gastric Cardiac Cancer
}

Qin Huang,,$^{1,2^{*}}$ Matthew Read, ${ }^{3}$ Jason S. Gold, ${ }^{4}$ Xiaoping Zou ${ }^{5}$

${ }^{1}$ Department of Pathology of Nanjing Drum Tower Hospital, Nanjing, China

${ }^{2}$ Department of Pathology and Laboratory Medicine, Veterans Affairs Boston Healthcare System, Harvard Medical School/Brigham and Women’s Hospital, Boston, USA.

${ }^{3}$ Department of Surgery, St Vincent's Hospital, Melbourne, Australia.

${ }^{4}$ Department of Surgery, Veterans Affairs Boston Healthcare System, Harvard Medical School/Brigham and Women’s Hospital, Boston, USA.

${ }^{5}$ Department of Gastroenterology of Nanjing Drum Tower Hospital affiliated to Nanjing University Medical School, Nanjing, China

\section{*Corresponding author:}

Qin Huang, Department of Pathology and Laboratory Medicine, Veterans Affairs Boston Healthcare System and Harvard Medical School, 1400 VFW Parkway, West Roxbury, MA 02132, U.S.A.

Email: qin.huang@va.gov; qinhuang0122@gmail.com

Office Phone: 857-203-5020.

FAX: 857-203-5623.

\begin{abstract}
Aim. Gastric cardiac carcinoma (GCC) is controversial and currently grouped with esophageal adenocarcinoma (EAC) as adenocarcinoma of the gastroesophageal junction (GEJ). Recently, diagnostic criteria of the GEJ were established and GCC can be separated from EAC. We aimed to view published evidence to clarify the GCC entity for better patient management.
\end{abstract}

This is the author manuscript accepted for publication and has undergone full peer review but has not been through the copyediting, typesetting, pagination and proofreading process, which may lead to differences between this version and the Version of Record. Please cite this article as doi: 10.1111/1751-2980.12945

This article is protected by copyright. All rights reserved. 
Methods. We searched key relevant words in Pubmed and Google Scholar over past decades, evaluated crucial findings from high-quality papers, and compared the key evidence between GCC and EAC.

Results. GCC arises in cardiac mucosa located between $3 \mathrm{~cm}$ below and $2 \mathrm{~cm}$ above the GEJ line. Compared to EAC, GCC is more like gastric cancer with a higher proportion of female patients, younger age, lower propensity for reflux disease, wider histopathologic spectrum, and more complex genomic profiles. Although GCC pathogenesis mechanisms remain unknown, the two-etiology proposal is appealing: in high-risk regions, the Correa pathway with Helicobacter pylori infection, low acid, and intestinal metaplasia-dysplasia-carcinoma may apply, while in low-risk regions, the sequential event from reflux toxin-induced mucosal injury, high acid, to intestinal metaplasia-dysplasia-carcinoma may occur. In early GCC, a minimal risk of nodal metastasis argues for a role of endoscopic therapy, whereas in advanced GCC, gastric cancer staging rules and treatment strategy appear to be more appropriate than the esophageal cancer staging scheme and therapy for better prognosis stratification and treatment.

Conclusions. GCC demonstrates clinicopathologic and genomic features more like gastric cancer than EAC. GCC patients should be managed in a multidisciplinary approach.

\section{Introduction}

Controversy exists regarding the classification of cancers around the gastroesophageal junction (GEJ) and the impact that this has on patient management and prognostication. The primary 
cancer in this region is gastric cardiac carcinoma (GCC). GCC occurs in the gastric cardia and typically has its epicenter located between three centimeters below and two centimeters above the GEJ (Figure 1). ${ }^{1,2}$ Traditionally, GCC was considered a subset of gastric cancers and was treated as such. However, GCC was classified from gastric cancer to esophageal cancer within the group of "adenocarcinomas of the esophagus and oesophogastric junction NOS".3,4 This change persisted in the eighth edition of AJCC and the fifth edition of the World Health Organization Digestive System Tumors. ${ }^{4,5}$ Due to the grouping of esophageal adenocarcinoma (EAC) and GCC into one single entity, the literature on GCC and EAC has become confusing. This confusion is further compounded by the technical challenges. In the presence of Barrett's esophagus (BE), the true anatomical GEJ line may separate from the squamocolumnar junction and become difficult for correct identification at endoscopy and in pathology. Due to the regrouping of GCC and misclassification, the incidence of EAC was incorrectly reported to be rising in some places. ${ }^{6}$ However, since 2007 when the histologic landmarks of the GEJ were established, ${ }^{7}$ tumors of the GEJ region have been more accurately diagnosed and classified. Overwhelming evidence from these recent studies indicates that GCC is a separate entity to EAC. Although the exact tumorigenesis mechanisms for GCC and EAC remain unknown, robust evidence suggests that GCC shares more similarities to gastric cancer than to EAC. In this brief review, we share recent insights into the epidemiology, histopathology, and genetics of GCC and hope that this will stimulate further investigations in order to improve the clinical management of GCC patients.

\section{Cardiac Mucosa Present in a Region about $3 \mathrm{~cm}$ below and $2 \mathrm{~cm}$ above Gastroesophageal Junction}

GCC arises in gastric cardiac mucosa (Figure 1). Cardiac mucosa is composed of primarily pure mucous and mixed mucoxyntic glands in addition to occasional parietal cells and scattered endocrine cells, but no chief cells (Figure 2). ${ }^{8}$ In the proximal stomach, cardiac mucosa is concentrated in the gastric cardia with a mean length of $13 \mathrm{~mm}$ (range 2-63 mm) ${ }^{9}$ and may also 
present underneath the distal esophageal squamous epithelium as "superficial esophageal (cardiac) glands”10-13 with a mean length of $4 \mathrm{~mm}$ (range 1-26 mm) in patients without long segment BE. ${ }^{9}$ Superficial esophageal cardiac glands in over 97\% of Chinese patients extend proximally within $10 \mathrm{~mm}$ (mean $4 \mathrm{~mm}$; range 1-13 mm) above the GEJ line in subjects without a history of reflux disease and BE. ${ }^{13}$ It is interesting to know that superficial esophageal cardiac glands are widely present in American adults, as revealed by three-dimensional optical coherence tomography. ${ }^{14}$ These superficial esophageal cardiac glands export their contents via the cardiac glandular ducts through the esophageal squamous epithelium into the distal esophageal lumen to protect squamous epithelium against acid and bile reflux toxins (Figures 3a,3b). Because of associated chronic inflammation, cardiac glands and their ductal epithelium may undergo goblet cell/intestinal metaplasia (Figure 3b). The prevalence of intestinal metaplasia of those glands appears to be lower than that in long segment BE. ${ }^{15-17}$ The length of superficial esophageal cardiac glands may increase, as a result of aging, obesity, and gastroesophageal reflux disease. ${ }^{18,19}$

Overwhelming evidence has demonstrated the congenital nature of gastric cardiac mucosa in fetuses, neonates, and adults in various racial/ethnic populations, ${ }^{8}$ such as Japanese, ${ }^{9}$ Korean, ${ }^{20}$ Dutch, ${ }^{21,22}$ German, ${ }^{23}$ American, ${ }^{24-26}$ and Chinese. ${ }^{13}$ Investigators with the viewpoint of metaplastic cardiac mucosa believe that only pure mucous glands are qualified as cardiac glands, whereas mucoxyntic glands mixed with parietal cells in the gastric cardia are not. ${ }^{20,27,28}$ In fact, the concentration of pure mucous glands decreases gradually from the GEJ to the distal stomach with a steady presence of oxyntic glands (Figure 2). The component of the mucoxyntic mucosa is an inseparable part of the gastric cardia.

In the cardiac mucosa of the proximal stomach and superficial esophageal cardiac glands, pancreatic acinar metaplasia is common and has been reported with a prevalence of $13 \%$ in Americans, ${ }^{25} 17.2 \%$ in Europeans, ${ }^{29}$ and 35\% in Chinese. ${ }^{30}$ Pancreatic acinar metaplasia in the cardiac mucosa was considered to be congenital and not associated with reflux disease or Hp- 
related carditis, ${ }^{29}$ but significantly more commonly observed in cases with GCC for unknown mechanisms. ${ }^{30-32}$

In GCC patients, chronic gastric carditis is widespread, frequently associated with erosion of the distal esophageal epithelium, pancreatic acinar metaplasia, and occasional goblet cell/intestinal metaplasia. Because of subtle mucosal alterations and unique anatomic location, early GCC has been reported to be missed in up to $42 \%$ of upper endoscopic examinations. ${ }^{33}$ As a result, the majority of GCC cases are diagnosed at advanced stages with nodal and distant metastases.

\section{Unique Pathologic Characteristics}

Unlike EAC which shows a simple tubular/papillary adenocarcinoma morphology, ${ }^{34,35}$ GCC is much more complex with a much broader histopathologic spectrum, covering all five subtypes of gastric adenocarcinomas (tubular, papillary, mucinous, poorly cohesive, and mixed ) as well as uncommon entities (Table 1), such as adenosquamous carcinoma, neuroendocrine carcinoma, carcinosarcoma, and choriocarcinoma, etc. ${ }^{34-38}$ Recently recognized uncommon gastric adenocarcinoma subtypes, such as hepatoid adenocarcinoma, Epstein-Barr Virus (EBV)-related adenocarcinoma with lymphoid stroma, and pancreatic acinar-like adenocarcinoma, have a predisposition for the gastric cardia. ${ }^{32,36,38-41}$ In a worldwide Pubmed search for gastric carcinosarcoma, ${ }^{42}$ investigators reported a predominance of this exceedingly rare cancer in the gastric cardiac region of Chinese patients, compared to that in Japanese and other patient populations. The gastric cardia is also one of the most common regions of the stomach for primary gastric melanoma to occur. ${ }^{43}$

Once diagnosed, early GCC has a natural history of very slow progression. Two separate case reports from Japan described seven- and 12-year intervals between the initial diagnosis of early GCC and death from other causes in two elderly Japanese male patients who were deemed unfit for either endoscopic or surgical intervention. ${ }^{44,45}$ Similar findings were also reported in Chinese patients from the Henan Province in China in two case-series reports with a combined cohort of 38 GCC patients discovered at mass screening campaigns. These patients were not treated for a 
variety of reasons. After six- and 14-year follow-up periods, the estimated 5-year survival rates in those patients were $61.5 \%$ and $76.5 \%$, respectively. ${ }^{46,47}$ In contrast, advanced GCCs demonstrate aggressive behavior with the 5-year overall survival rate of about $14 \%$ in the United States. ${ }^{48}$

At present, the only hope to improve the outcomes of GCC patients is early detection with prompt resection of early lesions, defined as invasive carcinoma limited to mucosa and submucosa, regardless of the lymph node status. Currently, early GCC has not only been diagnosed at the early pT1 stage in an ever-growing number of cases, but also has been successfully treated by endoscopic therapy with 5-year overall and disease-free survival rates over $90 \%$, similar to those by surgical resection. ${ }^{49}$ Given lower long-term resection-related adverse events, better preservation of function, and shorter hospital stays, compared to conventional surgical resection, ${ }^{49}$ endoscopic therapy has gradually and surely replaced surgical intervention for resection of early GCC in selected patients with minimal or no risk of nodal metastasis, as seen in endoscopic therapy for early EAC. ${ }^{30,50-54}$ In a multicenter study with 495 early GCC radical resection cases, investigators did not find a single case with nodal metastasis in 193 intramucosal carcinomas, regardless of tumor size, gross pattern, histology type, differentiation, the presence or absence of ulceration, with or without invasion of the distal esophagus, unlike early distal gastric non-cardiac carcinoma. ${ }^{54}$ Although submucosal invasion is much more frequently identified in up to $61 \%$ of early GCC cases, the prevalence of lymph node metastasis remained significantly lower $(10.9 \%, 33 / 302)$ in early GCC than in early gastric noncardiac carcinomas $(27.9 \%, 368 / 1318$, p < 0.0001). No lymph node metastasis was identified in rare carcinomas, such as neuroendocrine carcinoma, carcinoma with lymphoid stroma, and adenosquamous carcinoma of the gastric cardia. ${ }^{54}$ The exceptionally low frequency of lymph node metastasis in early GCC may be related to the unique anatomic structure of the gastric cardia with markedly thickened muscularis mucosae and submucosa. ${ }^{55}$ On the other hand, micropapillary adenocarcinoma, lymphovascular invasion, tumor budding, tumor size $>3 \mathrm{~cm}$ and submucosal invasive poorly differentiated GCC were found to be independent risk factors 
for nodal metastasis. ${ }^{54,56}$ These findings may have considerable impact on the current clinical management of patients with early GCC.

Distal esophageal extension of GCC is not uncommon (Figures 3c, 3d). In a single-center retrospective clinicopathologic study of early gastric carcinomas, ${ }^{57}$ over $30 \%$ of early GCCs showed focal invasion of the distal esophagus up to $0.41 \mathrm{~cm}$ in length in patients without the evidence of long segment BE; in those cases, focal short segment columnar-lined esophagus was present in about $50 \%$ of cases in which intestinal metaplasia was rare or absent. ${ }^{35,57}$ On the other hand, although BE is the precursor of EAC, the majority of reported EAC cases are diagnosed at initial biopsy without prior endoscopic surveillance, ${ }^{58,59}$ raising the possibility of being "other phenotype of EAC". ${ }^{60}$ Given the fact that most de novo EAC tumors are located at or $1-2 \mathrm{~cm}$ above the GEJ in patients without long segment BE, we believe that this "other phenotype of EAC” is GCC with distal esophageal extension, which is frequently misclassified as EAC. ${ }^{3}$ Over the past decades, a growing body of evidence supports the categorization of tumors with epicenters located $3 \mathrm{~cm}$ below and $2 \mathrm{~cm}$ above the GEJ as GCC, not EAC. ${ }^{1,2,35,61}$ First, cardiac mucosa with distal esophageal extension is common and known to be associated with aging and reflux diseases (Figures 1-3). Second, although distal esophageal cardiac mucosa may undergo intestinal metaplasia, the frequency of goblet cell/intestinal metaplasia is much lower than that seen in long-segment BE and EAC. ${ }^{17-19}$ Third, the prevalence of goblet cell/intestinal metaplasia in cardiac mucosa adjacent to EAC was reported to be about 50\% in American and British patients. ${ }^{60,62}$ The evidence suggests the existence of at least two phenotypes of EAC: i.e., EAC with either a high or low prevalence of goblet cells/intestinal metaplasia. The EAC cases with a low prevalence of goblet cell/intestinal metaplasia include GCC tumors with esophageal extension (Siewert II), whereas those with a high prevalence of goblet cell/intestinal metaplasia are pure EAC (Siewert I). ${ }^{63}$ This proposal is also supported by the recent evidence in epidemiology and genomics on GCC.

\section{Epidemiologic Features}


The epidemiology of GCC is much more complex than that of EAC. Available evidence suggests that epidemiologic features of GCC are more like those of gastric non-cardiac cancer than those of EAC. According to the World Health Organization statistical data, there were about 260,000 GCC cases in 2012 worldwide with considerable geographic heterogeneity. ${ }^{64,65}$ GCC occurs heavily in China and central Asian countries with over 52\% of GCC cases worldwide in China, but rarely in Japan and Korea as well as most European, African, and American countries. ${ }^{65}$ In single center studies, the percentage of GCC resection cases was reported to range from $29 \%$ to $68 \%$ of gastric cancers in China, ${ }^{30,66}$ over $50 \%$ in northern Iran, ${ }^{67}$ more than $40 \%$ in Mongolia, ${ }^{68}$ $30.3 \%$ in northern Turkey, ${ }^{69}$ and $23 \%$ in Pakistan. ${ }^{70}$ In contrast, the prevalence of GCC in gastric cancer resections remains low in Japan and Korea, accounting for 2.5\% (79/3144) reported at the Japanese National Cancer Center Hospital in $2000^{71}$ and $4.9 \%$ at the Samsung Medical Center in Korea in 2018. ${ }^{72}$ This very low rate of GCC in Japan has been constant over the past 70 years, despite the dramatic changes toward a Western lifestyle among the Japanese population. ${ }^{73}$ In the United States, GCC accounted for about 24\% of gastric cancer over the period from 1978 to $2005 .{ }^{74}$ Geographic heterogeneity in GCC appears to be genetic-related because some risk factors of GCC may be ancestry-specific. ${ }^{75}$ Unlike a rising trend in the incidence of EAC, the incidence of GCC has remained consistently low in the United States since $1996^{76}$ or has decreased in the United Kingdom and the Netherlands. ${ }^{77,78}$ Because of the geographic and racial/ethnic heterogeneity, GCC demonstrates various characteristics in risk factors, pathology, genetics, and outcomes between high- and low-risk regions of the world.

GCC is a multifactorial gastric disease and the most important environmental risk factor is Helicobacter pylori (Hp) infection. In a recent meta-analysis of 34 original research papers on GCC, investigators reported a summary relative risk [RR] of 1.08 (95\% confidence interval [CI] $0.83-1.40)$. However, the RR is much higher in high-risk regions $(\mathrm{RR}=1.98$; $95 \% \mathrm{CI}$ : $1.38-$ 2.83), compared to low-risk regions $\left(\mathrm{RR}=0.78\right.$; $95 \% \mathrm{CI}$ : 0.63-0.97) ${ }^{79}$ Specifically, the relationship of Hp infection and GCC is positively correlated in Chinese patients, but negatively or inversely correlated in American ${ }^{80}$ and most Northern European patients, as reported by a 
meta-analysis with 12 case-control studies nested within prospective cohorts. ${ }^{81}$ In a single center study in Chinese GCC patients, the prevalence of Hp infection was 53\%. ${ }^{82}$ In Korean GCC patients, a meta-analysis of 11 case-control studies reported a significantly positive correlation with $\mathrm{Hp}$ infection ( $\mathrm{RR}=2.95,95 \% \mathrm{CI}$ : 2.19-3.98). ${ }^{83}$ Among various Hp variants, the vacA c1 genotype was found to be strongly correlated with an increased risk $(\mathrm{RR}=14.11)$ of GCC in Iranian patients, and is used as the primary bacterial biomarker for GCC risk in Iranian men older than 55 years. ${ }^{84}$ The same group of Iranian investigators also described an inverse association of GCC with the Hp vacA c2 genotype in combination with cag PAI genotypes in Iranian patients. ${ }^{85}$ The virulence of various Hp strains may have different effects among various populations, supporting the existence of etiologically distinct subtypes of GCC that occur to a higher or lesser extent in diverse populations with different gastric cancer incidences. ${ }^{48,79}$ Although there is significant evidence of the relationship between Hp infection and GCC tumorigenesis in high-risk regions, Hp infection alone may not be sufficient for GCC development, ${ }^{86}$ and other factors may also play important roles. In contrasts, Hp infection confers between a 40-60\% reduction in EAC development. ${ }^{87}$

In recent years, EBV infection has been identified as one of key infectious agents for gastric cancer with a prevalence of about 5-16\% of all gastric cancers, ${ }^{36,41,88,89}$ especially for GCC. ${ }^{88,89}$ In contrast, EBV infection related EAC has not been described. Immunohistochemical analysis reveals that EBV-associated gastric carcinomas contain more tumor infiltrating lymphocytes than actual tumor cells, comprising on average of 50\% (CD8+) $\mathrm{T}$ cells and 20\% (CD68+) macrophages, and express programmed death-ligand 1 in $70 \%$ of EBV-associated gastric carcinomas. $^{90,91}$

Other infectious agents such as human papillomavirus DNA and P16 ${ }^{\mathrm{INK} 4 \mathrm{~A}}$ expression have been identified concurrently in esophageal squamous cell carcinoma and GCC.9 ${ }^{92}$ As to bacteria, gastric cardiac mucosa of Chinese patients harbors 64 species of resident bacteria responsible for chronic gastric carditis, especially Hp, Lactobacillus Spp., Acinetobacter ursingii, and Streptococcus agalactiae. ${ }^{93}$ These gastric cardiac microflorae may play important roles in DNA 
repair and epigenetic changes and promote cancer progression in chronic carditis, which is significantly enhanced by the relative abundance of $\mathrm{Hp}$ in that population..$^{93}$

Aging is a well-known risk factor commonly seen in most epithelial malignancies such as GCC. The incidence of gastric cancer increased by 25\% between 2007 and 2017, of which a change in the worldwide population age structure contributed $19 \% .{ }^{94}$ In a Chinese patient population, the average age of GCC patients at diagnosis is over 60 years, ${ }^{95}$ which is much younger than that (70 years) of EAC patients. ${ }^{4}$ Advanced age was reported to be a significant independent risk factor for GCC (RR $=9.83,95 \%$ CI 2.32-41.67). ${ }^{4,96}$ This age-related disease may be linked to the aging associated gene, Sirt-1. In single center studies, GCC tumors with Sirt-1 gene overexpression were more frequently found to have lymphovascular invasion, lymph node and distant organ metastases, and poorer prognosis, compared to those without Sirt-1 gene overexpression. ${ }^{97}$ Sirt-1 gene over-expression was also present in advanced GCC in Turkish patients, but not present in early GCC, poorly cohesive carcinoma/signet-ring cell carcinoma, female patients, and patients younger than 45 years old. ${ }^{98}$ The underlying detailed molecular mechanisms on the role of the Sirt-1 gene mutation in GCC tumorigenesis are unknown.

Unlike EAC with a dramatic male-female ratio up to $9: 1,{ }^{79}$ a substantial number of GCC patients are post-menopausal women with a male-female ratio of about 3:1. ${ }^{54,65}$ The mechanistic role of estrogen receptors in gastric cancer tumorigenesis has been suggested in a recent genome analysis of 521 gastric cancer associated genes, in which estrogen-related receptor gamma in gastric cancer was revealed to be inversely correlated with the expression of Wnt signalingassociated genes in gastric cancer patients and function as a tumor suppressor in gastric cancer. ${ }^{99}$ Cigarette smoking has significant adverse effects on GCC development. In a pooled analysis of ten population-based case-control studies and two cohort studies in Caucasian patients with GCC $(n=1450)$ versus those with EAC $(n=1540)$, the investigators reported strong associations of smoking with GCC $(\mathrm{RR}=2.18,95 \% \mathrm{CI}: 1.84$ to 2.58$)$ and EAC $(\mathrm{RR}=1.96,95 \% \mathrm{CI}: 1.64$ to 2.34). The effect was also shown to be strongly dose-responsive. ${ }^{100,101}$ Similar results were also found in a Chinese population. ${ }^{96}$ In contrast, alcohol consumption appears not to be a risk factor 
for GCC, as discovered by a population-based study in Shanghai, China ${ }^{102}$ and a populationbased prospective cohort study in Norway. ${ }^{101}$

According to two large cohort studies, ${ }^{102,103}$ dietary factors such as a pro-inflammatory diet, e.g. meat, fatty food, sugar and confectionery, had a strong positive correlation with inflammation; the inflammatory potential of this diet increased with age; in contrast, consumption of legumes, vegetables, fruits, condiments and sauces, fruit juices, coffee, tea, cereal products, and alcoholic beverages had anti-inflammatory capacity. ${ }^{103}$ The effects of the diet on gastric cancer were shown to be more conspicuous for GCC than for gastric non-cardiac cancer. ${ }^{102,103}$

An increased risk of GCC has been demonstrated in patients with a positive personal or family history of either gastric and/or esophageal cancer by single-center case-control studies in Chinese patients, ${ }^{87,96}$ but not in Finnish patients. ${ }^{104}$ Chinese GCC patients with a positive family history of gastric cancer had a higher risk of GCC than those without. ${ }^{87}$ On the other hand, GCC patients may have a high risk for coincidence of esophageal squamous cell carcinoma, especially in those with a positive family history of both cancers, supporting a shared genetic predisposition between esophageal squamous cell carcinoma and GCC. ${ }^{105}$ Recent genome-wide association studies in Chinese patients discovered a novel variant gene, the phospholipase $\mathrm{C}$ epsilon gene (PLCE1) at 10q23, that is strongly associated with both cancers. ${ }^{106-108} \mathrm{~A}$ meta-analysis revealed a significant association of the PLCE1 rs2274223 G allele with the risk of GCC (RR = 1.56; 95\% CI: 1.47-1.64) and esophageal squamous cell carcinoma $(\mathrm{RR}=1.33$; 95\% $\mathrm{CI}: 1.21-1.45)$ in Chinese patients, ${ }^{105}$ suggesting inherited susceptibility for both cancers in the study population.

In a case-control study on single nucleotide polymorphisms in early-onset gastric cancer of a Chinese Han population, individuals with a familial hereditary cancer background including the risk alleles PLCE1 rs2274223 and PTGER4/PRKAA1 rs13361707 were reported to have three times greater susceptibility to GCC than those without. ${ }^{109}$ In contrast, the vast majority of EAC cases are sporadically acquired, whereas only $7 \%$ of cases were considered to be familial with clusters of EAC cases in families with a rare autosomal dominant genetic trait or attenuated 
familial adenomatous polyposis, mismatch repair deficiency, or rare gene mutations. ${ }^{110}$ No specific genetic predisposition has been illustrated in EAC.

The relationship between obesity and GCC has been the subject of intense investigation. A recent meta-analysis of 24 prospective studies on body mass index and GCC risk exhibited a positive association ( $\mathrm{RR}=1.21$ for overweight and $\mathrm{RR}=1.82$ for obesity) with a linear doseresponse pattern. ${ }^{111}$ In the United States, the National Institute of Health-American Association of Retired Persons Study with a sample size of 218,854 participants reported a strong positive association for obesity and risk of GCC (RR $=3.67$; 95\% CI:2.00-6.71). ${ }^{112}$ However, this positive association is not confirmed in a population-based cohort study in Norway ${ }^{113}$ and China. ${ }^{114}$ The role of obesity in GCC development may be related to an increased incidence of gastroesophageal reflux disease in obese patients in Western countries. ${ }^{15,115,116}$

In Western countries, gastroesophageal reflux disease is widespread and significantly associated with EAC, but only weakly correlated with increased risk of GCC. ${ }^{1,117}$ In a population-based case-control study in Sweden, Lagergren et al reported the absence of reflux disease in up to 71\% of GCC patients; even in patients with severe reflux disease, the risk of GCC (RR = 4.4) was much lower than that of EAC $(\mathrm{RR}=43.5){ }^{1}$ Therefore, the authors could not establish a causal relationship between reflux disease and GCC. ${ }^{1}$ However, the risk for EAC and GCC remained increased even after anti-reflux surgical therapy, suggesting the existence of other important risk factors. ${ }^{118}$ For the GCC high-risk Chinese population, reflux disease and BE are uncommon and were found not to be independent risk factors of GCC in one single center study ${ }^{96}$ In the GCC low-risk European population, severe chronic atrophic gastritis was reported to have a 10-fold increased risk of GCC in Hp-negative patients, following the reflux-atrophy-intestinal metaplasia-GCC sequence. ${ }^{119,120}$ These results suggest an etiology other than Hp infection, such as reflux disease, for GCC development in low-risk populations. ${ }^{121}$

\section{Tumorigenesis Mechanisms and Role of Stem and stem-like cells}


While the pathogenesis mechanisms of GCC remain obscure, the two-etiology pathway hypothesis has been proposed for GCC development in low- and high-risk populations by the McColl group (Figure 4). ${ }^{121}$ Also, stem and stem-like cells in the gastric cardiac/GEJ region may play critical roles in GCC tumorigenesis. ${ }^{122}$

Obesity-reflux associated pathway. In the GCC low-risk region with a low prevalence of Hp infection, patients may have central obesity, high animal fat intake history, frequent duodenalgastric reflux with high gastric acid that changes microenvironment in the gastric cardia. In a repair/regenerative response, gastric cardiac mucosa may have chronic inflammation with destruction of functional glands, leading to atrophy, goblet cell/intestinal and pancreatic metaplasia, and to dysplasia/carcinoma in genetically vulnerable subjects. ${ }^{15,120,121,123}$

Hp infection associated pathway. In the GCC high-risk region with a high prevalence of Hp infection, GCC tumorigenesis may follow the Correa pathway from the Hp infection, chronic inflammation, low-volume gastric acid production, goblet cell/intestinal and pancreatic metaplasia, to dysplasia and carcinoma. ${ }^{48,123}$

Stem and stem-like cells, such as undifferentiated primitive cells, pluripotential stem cells, and residual embryonic stem cells, ${ }^{122,124}$ are present in the gastric cardia and GEJ region. These stem cells may differentiate into either squamous or columnar cells in response to the changes of local microenvironments. In cardiac glands, primitive stem cells near the crypt base were selectively highlighted immunohistochemically by Lgr5, which is an intestinal stem cell marker, suggesting the potential capability of intestinal differentiation in these Lgr5-positive cells ${ }^{124}$. At the squamocolumnar junction of the GEJ, transitional basal cells (p63+ KRT5+ KRT7+) have been shown to serve as a source of progenitors for the transitional epithelium that can differentiate into intestine-like epithelium with metaplastic goblet cells upon ectopic expression of CDX2. ${ }^{122,125}$ These features may help explain a wide histopathologic spectrum of GCC.

The landmark papers on the genomics of gastric and esophageal carcinomas published by The Cancer Genome Atlas (TCGA) Network in 2014 and 2017 have profoundly changed the field of gastric and esophageal cancer genomics. ${ }^{36,37}$ It is now established that among the four major 
molecular subtypes of gastric carcinomas (chromosome instability, genomically stable, microsatellite unstable, and EBV-associated), the chromosomal instability subtype is most common (70-80\%) in GCC with the other three sub-types presenting much less in frequency. ${ }^{36}$ In contrast, almost all EAC tumors show molecular profiles of the chromosomal instability subtype, suggesting EAC to be a gastric, not esophageal, carcinoma at the genomic level. ${ }^{37}$ The only single "EAC" tumor with molecular features of the genomically stable subtype (signet-ring cell carcinoma) described in the study occurred in the GEJ region (i.e., part of GCC). ${ }^{37}$ However, there exist some differences in gastric cancer genomic profiles between Western (TCGA) and Eastern (Asian Cancer Research Group) gastric cancer patient populations. ${ }^{126}$ Unlike the TCGA data with a predominance of the chromosomal instability subtype in GCC, ${ }^{36,37}$ the Eastern results demonstrated the percentages of $8.4 \%$ for MSS/TP53-, 17.7\% for MSS/TP53 ${ }^{+}, 5.9 \%$ for MSI, and $10.9 \%$ for MSS/EMT molecular subtypes in GCC. ${ }^{126}$ The marked variation in the prevalence of TP53 gene mutation reflects mechanistic heterogeneity in GCC between these two major ethnic patient populations and may help explain the differences in clinicopathology of GCC between Western and Eastern populations.

\section{Staged as Gastric Cancer for Better Prognostic Stratification.}

Accurate prognostic stratification of GCC patient survival remains an unmet, but urgent need. GCC is traditionally classified and staged as gastric cancer and demonstrates better prognosis than EAC, especially for stage III GCC patients. ${ }^{35,127,128}$ In 2009, the $7^{\text {th }}$ edition of the AJCC staging manual required classification and staging of GCC as EAC. ${ }^{3}$ This dramatic change in paradigm has invited intense debate on the predictive value of this decision on prognosis of GCC patients. ${ }^{129-131}$ The International Gastric Cancer Association organized a 24-center study with 25,411 eligible gastric cancer resection cases. ${ }^{132}$ They reported a clear stratification of $\mathrm{T}$ and $\mathrm{N}$ categories in a new gastric cancer staging system for patient survival and required staging GCC as gastric cancer. ${ }^{132}$ Although the $8^{\text {th }}$ edition of the AJCC staging manual used the same patient dataset and adopted this modification for the most part, GCC tumors with esophageal extension 
are still required to be staged as esophageal carcinoma. ${ }^{5}$ Recent studies on GCC staging compared patient survival stratified with the staging schemes of the $8^{\text {th }}$ edition of this cancer staging manual between gastric and esophageal systems. ${ }^{133,134}$ Investigators reported significantly better survival stratification for all four major stages of GCC in the gastric cancer staging system, compared to those in the esophageal cancer staging system. ${ }^{133,134}$ However, "neither the esophageal nor the stomach staging system is flawless in predicting survival” in patients with advanced GCC tumors. ${ }^{131}$ The available evidence at present, although not perfect, suggests the superiority of the application of the gastric cancer staging rules for GCC staging in advanced GCC cases. This will help better triage and manage GCC patients clinically. Further investigation on this staging issue will continue.

\section{Strategies for Clinical Management}

Appropriate GCC patient clinical management depends on tumor staging. For early GCC staged at pT1a with or without esophageal invasion, the risk of lymph node metastasis is very low ${ }^{130}$ and endoscopic therapy is favored as the primary option. The decision on endoscopic versus surgical resection for pT1b GCCs requires a clear understanding of the risk of nodal metastasis. In general, the criteria for endoscopic resection in early GCC include tumor size $<3 \mathrm{~cm}$, wellmoderate differentiation, uncommon carcinomas such as adenosquamous carcinoma, neuroendocrine carcinoma, and EBV-associated carcinoma with lymphoid stroma, and the absence of lymphovascular invasion or tumor budding; ${ }^{130,135}$ otherwise, radical surgical resection with lymphadenectomy is preferred (Table 3).

Once a GCC tumor invades the muscularis propria, radical surgical resection with a thorough nodal dissection is required for curative resection. According to a nationwide retrospective study of 2807 GCC radical resection cases in Japan, nodal metastasis occurred primarily in the abdominal nodes around the gastric cardia. ${ }^{136}$ The prevalence of mediastinal nodal metastasis depends upon the length of esophageal invasion in advanced GCC with a significantly higher frequency if the distance from the gastroesophageal junction to the proximal edge of GCC is 
over $3 \mathrm{~cm}$ for the upper and middle mediastinal nodes and over $2 \mathrm{~cm}$ for the lower mediastinal nodes. ${ }^{137,138}$ In GCC with esophageal extension less than $2 \mathrm{~cm}$, the probability for the lower mediastinal nodal metastasis is too low $(<5 \%)$ to make nodal dissection in the lower mediastinum necessary. ${ }^{138}$ In addition, complete nodal clearance around the distal stomach showed marginal survival benefits for patients with GCC tumors in size of $4 \mathrm{~cm}$ or less. ${ }^{136}$ An abdominal approach, even for GCC tumors with $<3 \mathrm{~cm}$ esophageal extension, is a preferred surgical resection method because of better outcomes, according to a randomized controlled trial in Japan that demonstrated significant benefits of lower complications, lower mortality, and better survival, compared to thoracic surgery. ${ }^{139}$ Because the data from the multicenter investigation in Japan showed a very low ( $<1 \%$ ) nodal metastasis rate at nodal stations 4sa, 4sb, 4d, 5, and 6 in GCC $<4 \mathrm{~cm}$ in size, both Japanese and Chinese Gastric Cancer Treatment Guidelines recommended proximal gastrectomy with D1 lymphadenectomy at stations 3b, 8a, 9, and 11p. ${ }^{138,140}$ Most recently, a prospective 42-center study was conducted in Japan with a total of 481 eligible advanced GCC (Siewert II) cases. The results suggest that total gastrectomy and para-aortic nodal dissection were not necessary for GCC with distal esophageal extension $<2.0$ $\mathrm{cm}$; instead, proximal gastrectomy with an abdominal transhiatal approach along with lymph node dissection at abdominal nodal stations 1, 2, 3a, 7, 8a, 9, 11p, and 19 is recommended because of very low risk of metastasis in lymph nodes of the low mediastinum and abdominal hepatic/celiac regions. ${ }^{138,141}$ It should be noted that total gastrectomy may be associated with less clinical reflux, nausea and vomiting, and provide the patient with a better overall quality of life than proximal subtotal gastrectomy. ${ }^{142}$ In cases with nodal metastasis, adjuvant chemotherapy may be necessary to improve survival, especially for patients with GCC tumors staged at pT1N23 , even $<3.0 \mathrm{~cm}$ in size. ${ }^{143}$

\section{Summary}

GCC is heterogeneous with much more complex epidemiologic, clinical, pathologic, and genomic characteristics than EAC or gastric non-cardiac carcinoma. The current evidence suggests GCC to be part of gastric, not esophageal, carcinoma and patients should be managed 
individually in a multidisciplinary team approach. Further studies are warranted to determine the pathogenic mechanisms of GCC. With further knowledge, it is hoped that improved prevention and treatment strategies can be developed. It is the time to re-classify GCC with esophageal extension as a gastric, not esophageal, cancer for better patient management.

\section{ACKNOWLEDGEMENT}

Mathew Read is recipient of the Senior Lecturer Fellowship from the Royal Australasian College of Surgeons. We thank Mr. Yu Zha of Nanjing for his artistic modification of Figure 1.

Conflict of interest

All authors declare no competing interests.

\section{References}

1. Lagergren, J., Bergström, R., Lindgren, A., \& Nyrén, O. Symptomatic gastroesophageal reflux as a risk factor for esophageal adenocarcinoma. N. Engl. J. Med. 1999;340 (11): 825-831.

2. Conner, J.R., el-Zimaity, H., \& Riddell, R.H. In Histology for Pathologists, $5^{\text {th }}$ edition. Chapter 21 Esophagus. (ed. Mills, S.E.) 596 (Wolters Kluwer, Philadelphia, U.S.A. 2020).

3. American Joint Committee on Cancer Staging Manual. In AJCC Cancer Staging Manual, 7th (ed. Fleming, I.D.) 129-144 (New York, Springer, 2009).

4. Lam, A.K., Kumarasinghe, M.P. In WHO Classification of Tumors $5^{\text {th }}$ edition Digestive System (ed. The WHO Classification of Tumors Editorial BEard) 38-43 (Lyon, France. 2019).

5. American Joint Committee on Cancer Staging Manual. In AJCC Cancer Staging Manual, 8th (eds. Amin, M.B., Edge, S.B., \& Greene, F.L.) 203-220 (New York, Springer, 2017).

6. Ekstrom, A.M., et al. Evaluating gastric cancer misclassification: a potential explanation for the rise in cardia cancer incidence. J. Natl. Cancer Inst. 1999;91(9):786-790.

7. Srivastava, A., et al. Morphologic features are useful in distinguishing Barrett esophagus from carditis with intestinal metaplasia. Am. J. Surg. Pathol. 2007;31(11):1733-1741.

8. Huang, Q. Controversies of cardiac glands in the proximal stomach: a critical review. $J$. Gastroenterol. Hepatol. 2011;26(3):450-455.

9. Nakanishi, Y., et al. Distribution and significance of the oesophageal and gastric cardiac mucosae: a study of 131 operation specimens. Histopathology. 2007;51(4):515 - 519.

10. Yagi, K., Nakamura, A., Sekine, A., Umezu, H. The prevalence of esophageal cardiac glands: relationship with erosive esophagitis and nonerosive reflux disease (NERD) in Japanese patients. Endoscopy. 2006;38(6):652-653. 
11. Owen, D.A. In Histology for Pathologists. $3^{\text {nd }}$ edition (ed. Mills, S.E.) 589-602 (Lippincott Williams and Wilkins, Philadelphia, USA. 2007).

12. Fan, X.S., Feng, A.N., Zhang, L.H., Lauwers, G., Huang, Q. Esophageal columnar metaplasia is common in the distal esophagus of Chinese patients. Gastroenterology. 2010;138(5, Suppl 1), S-758.

13. Sun, Q., et al. Columnar-lined esophagus in Chinese patients with proximal gastric carcinomas. J. Dig. Dis. 2013;14(1):22-28.

14. Zhou, C., et al. Characterization of buried glands before and after radiofrequency ablation by using 3-dimensional optical coherence tomography (with videos). Gastrointest. Endosc. 2012;76(1):32-40.

15. Westerhoff, M., Hovan, L., Lee, C., \& Hart, J. Effects of dropping the requirement for goblet cells from the diagnosis of Barrett's esophagus. Clin. Gastroenterol. Hepatol. 2012;10(11):12321236.

16. Itskoviz, D., et al. Risk of Neoplastic Progression Among Patients with an Irregular Z Line on Long-Term Follow-Up. Dig. Dis. Sci. 2018;63(6):1513-1517.

17. Siddiki, H.A., et al. Intestinal metaplasia of the gastric cardia: findings in patients with versus without Barrett's esophagus. Gastrointest. Endosc. 2019;89(4):759-768.

18. Robertson, E.V., et al. Central obesity in asymptomatic volunteers is associated with increased intrasphincteric acid reflux and lengthening of the cardiac mucosa. Gastroenterology 2013;145(4):730-739.

19. Pinto, D., et al. Carditis: a relevant marker of gastroesophageal reflux disease. Data from a prospective central European multicenter study on histological and endoscopic diagnosis of esophagitis (histoGERD trial). Dis. Esophagus. 2019;32(1);doi: 10.1093/dote/doy073.

20. Park, Y.S., Park, H.J., Kang, G.H., Kim, C.J., \& Chi, J.G. Histology of gastroesophageal junction in fetal and pediatric autopsy. Arch. Pathol. Lab. Med. 2003;127(4):451-455.

21. De Hertogh, G., Van Eyken, P., Ectors, N., Tack, J., Geboes, K. On the existence and location of cardiac mucosa: an autopsy study in embryos, fetuses, and infants. Gut. 2003;52(6):791-796.

22. Marsman WA, van Sandick JW, Tytgat GN, ten Kate FJ, \& van Lanschot JJ. The presence and mucin histochemistry of cardiac type mucosa at the esophagogastric junction. Am. J. Gastroenterol. 2004;99(2):212-217.

23. Sarbia, M., Donner, A., Gabbert, H.E. Histopathology of the gastroesophageal junction: a study on 36 operation specimens. Am. J. Surg. Pathol. 2002;26(9):1207-1212.

24. Kilgore, S,P, et al. The gastric cardia: fact or fiction? Am. J. Gastroenterol. 2000;95(4):921924.

25. El-Serag, H.B., et al. Prevalence and determinants of histological abnormalities of the gastric cardia in volunteers. Scand. J. Gastroenterol. 2007;42(10):1158-1166.

26. Glickman JN, Fox V, Antonioli DA, Wang HH, Odze RD. Morphology of the cardia and significance of carditis in pediatric patients. Am. J. Surg. Pathol. 2002;26(8):1032-1039. 
27. Chandrasoma, P.T., et al. Histology of the gastroesophageal junction: an autopsy study. Am. J. Surg. Pathol. 2000;24(4):402-409.

28. Chandrasoma, P.T. Histologic definition of gastro-esophageal reflux disease. Curr. Opin. Gastroenterol. 2013;29(4):460-467.

29. Schneider, N.I., et al. Pancreatic acinar cells--a normal finding at the gastroesophageal junction? Data from a prospective Central European multicenter study. Virchows Arch. 2013;463(5):643-650.

30. Huang, Q., et al. Differences in Clinicopathology of Early Gastric Carcinoma between Proximal and Distal Location in 438 Chinese Patients. Sci. Rep. 2015;5:13439. doi: 10.1038/srep13439

31. Chen, L., et al. Risk Factors of Lymph Node Metastasis in 1620 Early Gastric Carcinoma Radical Resections in Jiangsu Province in China: A Multicenter Clinicopathologic Study. J. Dig. Dis. 2017;18(10):556-565.

32. Huang, Q., et al. Pancreatic acinar-like adenocarcinoma of the proximal stomach invading the esophagus. Hum. Pathol. 2012;43(6):911-920.

33. Ren, W., et al. Missed diagnosis of early gastric cancer or high-grade intraepithelial neoplasia. World J. Gastroenterol. 2013;19(13):2092-2096.

34. Wang, H.H., Antonioli, D.A., Goldman, H. Comparative features of esophageal and gastric adenocarcinomas: recent changes in type and frequency. Hum. Pathol. 1986;17(5):482-487.

35. Huang, Q., et al. Comparison of gastro-esophageal junction carcinomas in Chinese versus American patients. Histopathology. 2011;59(2):188-197.

36. Cancer Genome Atlas Research Network. Comprehensive molecular characterization of gastric adenocarcinoma. Nature. 2014;513(7517):202-209.

37. Cancer Genome Atlas Research Network. Integrated genomic characterization of esophageal carcinoma. Nature. 2017;541(7636):169-175.

38. Huang Q. In Gastric Cardiac Cancer (ed. Huang, Q) 119-146 (Springer International Publishing. 2018).

39. Xiao, C., et al. Hepatoid adenocarcinoma of the stomach: Nine case reports and treatment outcomes. Oncol. Lett. 2015;10(3):1605-1609.

40. Du, M.Z. et al. Risk factors of lymph node metastasis in 734 early gastric carcinoma radical resections in a Chinese population. J. Dig. Dis. 2019;19(10):586-595.

41. Carneiro F, et al. In WHO Classification of Tumors 5th edition Digestive System Tumors (ed. The WHO Classification of Tumors Editorial Board) 526-528 (Lyon, France. 2019).

42. Nie, L., et al. Histological heterogeneity and distributional difference of gastric carcinosarcoma: report of 4 cases and literature review. Pol. J. Pathol. 2018;69(4):366-375.

43. Wang, J., et al. Primary gastric melanoma: A case report with imaging findings and 5-year follow-up. World J. Gastroenterol. 2019;25(44):6571-6578.

44. Fujisaki, J., et al. Natural history of gastric cancer-a case followed up for eight years: early to advanced gastric cancer. Clin. J. Gastroenterol. 2012;5(5):351-354. 
45. Nikaido, M., et al. Twelve-year natural history of early esophagogastric junction cancer in an extremely old patient. Geiatr. Gerontol. Int. 2018;18(12):1648-1649.

46. Guanrei, Y., Songliang, Q., He, H., \& Guizen, F. Natural history of early esophageal squamous carcinoma and early adenocarcinoma of the gastric cardia in the People's Republic of China. Endoscopy. 1988;20(3):95-98.

47. Wang, G.Q., Wei, W.Q., Zhang, J.H.. Ai Zheng 2007;26(11):1153-1156 (In Chinese).

48. Correa, P. Gastric cancer: overview. Gastroenterol. Clin. North. Am. 2013;42(2):211-217.

49. Gong, E.J., et al. Comparison of long-term outcomes of endoscopic submucosal dissection and surgery for esophagogastric junction adenocarcinoma. Gastric Cancer. 2017;20(Suppl 1), 84-91.

50. Sharma P, Shaheen NJ, Katzka D, Bergman JJGHM. AGA Clinical Practice Update on Endoscopic Treatment of Barrett's Esophagus With Dysplasia and/or Early Cancer: Expert Review. Gastroenterology. 2020;158(3):760-769.

51. Tanaka, T., et al. Clinical and pathological evaluation of early cancer in the gastric cardia. Kurum Med. J. 1990;37(4):265-269.

52. van Sandick, J.W., et al. Pathology of early invasive adenocarcinoma of the esophagus oresophagogastric junction: implications for therapeutic decision making. Cancer. 2000;88(11):2429-2437.

53. Nesi, G., et al. Pathological predictors of lymph node involvement in submucosal gastric carcinoma: a retrospective analysis of long-term outcome. In Vivo. 2009;23(2):337-341.

54. Huang, Q., et al. Low risk of lymph node metastasis in 495 early gastric cardiac carcinomas: A multicenter clinicopathologic study of 2101 radical gastrectomies for early gastric carcinoma. Mod. Pathol. 2018;31(10):1599-1607.

55. Huang Q., et al. Marked Thickening of Muscularis Mucosae and Submucosa in the Gastric Cardia: A Histopathologic Study of 110 Surgical Resection Cases. J. Dig. Dis. 2020 Mar 29. doi: 10.1111/1751-2980.12860. [Epub ahead of print]

56. Du, M.Z., et al. Tumor budding and other risk factors of lymph node metastasis in submucosal early gastric carcinoma: A multicenter clinicopathologic study of 621 radical gastrectomies of Chinese patients. Am. J. Surg. Pathol. 2019;43(8):1074-1082.

57. Wang Y.H. et al. Predictive Factors and Long-term Outcomes of Early Gastric Carcinomas in Patients with Non-curative Resection by Endoscopic Submucosal Dissection. medRxiv: https://medrxiv.org/cgi/content/short/2020.04.04.20052852v1; BMC Gastro. 2020; submitted

58. Dulai, G.S., Guha, S., Kahn, K.L., Gornbein, J., \& Weinstein,W.M. Preoperative prevalence of Barrett's esophagus in esophageal adenocarcinoma: a systematic review. Gastroenterology. 2002;122(1):26-33.

59. Tramontano, A.C., et al. The impact of a prior diagnosis of Barrett's esophagus on esophageal adenocarcinoma survival. Am J Gastroenterol. 2017;112(8):1256-1264.

60. Sawas, T., et al. Identification of prognostic phenotypes of esophageal adenocarcinoma in 2 independent cohorts. Gastroenterology. 2018;155(6):1720-1728. 
61. Huang Q. Carcinoma of the gastroesophageal junction in Chinese patients. World $J$ Gastroenterol. 2012;18(48):7134-7140.

62. Leers JM, et al. Clinical characteristics, biologic behaviour, and survival after esophagectomy are similar for adenocarcinoma of the gastroesophageal junction and the distal esophagus. J. Thorac. Cardiovasc. Surg. 2009;138(3):594-602.

63. Siewert, J.R., Feith, M., Stein, H.J. Biologic and clinical variations of adenocarcinoma at the esophago-gastric junction: relevance of a topographic-anatomic subclassification. J. Surg. Oncol. 2005;90(3):139-146.

64. Ferlay, J., et al. Cancer incidence and mortality worldwide: sources, methods and major patterns in GLOBECAN 2012. Int J Cancer. 2015;136(5):E359-E386.

65. Colquhoun, A., Arnold, M., Ferlay, J., Goodman, K.J., Forman, D., Soerjomataram, I. Global patterns of cardia and non-cardia gastric cancer incidence in 2012. Gut. 2015;64(12):1881-1888.

66. Zhao CY, et al. [Analysis of the changing trends of frequency and localization of gastric cancers arising from different sites of the stomach in population of the high incidence area of esophageal and gastric cancers in Hebei province]. Zhonghua Zhong Liu Za Zhi. 2008;30(11): 817-820 (in Chinese).

67. Pourfarzi, F., Whelan, A., Kaldor, J., \& Malekzadeh, R. The role of diet and other environmental factors in the causation of gastric cancer in Iran-a population based study. Int. J. Cancer. 2009;125(8):1953-1960.

68. Matsuhisa, T., et al. Gastric mucosa in Mongolian and Japanese patients with gastric cancer and Helicobacter pylori infection. World J. Gastroenterol. 2015;21(27):8408-8417.

69. Fatih, A., Yasin, O., Hakan, D., Yavuz, A. Should every region use the same gastric cancer scanning and treatment approaches? let's reconsider: a northeastern turkey example. BMC Gastroenterol. 2016;16(1):120.

70. Yakoob, J., et al. Distribution of gastric carcinoma in an area with a high prevalence of Helicobacter pylori. Turk J Gastroenterol. 2017;28(2):98-103.

71. Okabayashi, T., et al. Early carcinoma of the gastric cardia in Japan: Is it different from that in the West? Cancer. 2000;89(12):2555-2559.

72. Choi, I.J., et al. Helicobacter pylori, Therapy for the Prevention of Metachronous Gastric Cancer. N. Engl. J. Med. 2018;378(12):1085-1095.

73. Honda, M., et al. Long-term Trends in Primary Sites of Gastric Adenocarcinoma in Japan and the United States. J. Cancer. 2017;8(11):1935-1942.

74. Wu H, Rusiecki JA, Zhu K, Potter J, Devesa SS. Stomach carcinoma incidence patterns in the United States by histologic type and anatomic site. Cancer Epidemiol Biomarkers Prev. 2009;18(7):1945-1952.

75. Popejoy, A.B., \& Fullerton, S.M. Genomics is failing on diversity. Nature. 2016;538(7624):161-164. 
76. Dubecz, A., Solymosi, N., Stadlhuber, R.J., Schweigert, M., Stein, H.J., \& Peters, J.H. Does the Incidence of Adenocarcinoma of the Esophagus and Gastric Cardia Continue to Rise in the Twenty-First Century? a SEER Database Analysis. J Gastrointest Surg. 2014:124-129.

77. Coupland, V.H., et al. Incidence and survival of esophageal and gastric cancer in England between 1998 and 2007, a population-based study. BMC Cancer. 2012;12:11. doi: 10.1186/1471-2407-12-11.

78. Dikken, J.L., et al. Increased incidence and survival for esophageal cancer but not for gastric cardia cancer in the Netherlands. Eur J Cancer. 2012;48(7):1624-1632.

79. Cavaleiro-Pinto, M., Pel eteiro, B., Lunet, N., \& Barros, H. Helicobacter pylori infection and gastric cardia cancer: systematic review and meta-analysis. Cancer Causes Control. 2011;22(3):375-387.

80. Kamangar, F., et al. Opposing risks of gastric cardia and noncardia gastric adenocarcinomas associated with Helicobacter pylori seropositivity. J. Natl. Cancer Inst. 2006;98(20):1445-1452.

81. Helicobacter and Cancer Collaborative Group. Gastric cancer and Helicobacter pylori: a combined analysis of 12 case control studies nested within prospective cohorts. Gut. 2001;49(3):347-353.

82. Huang, Q., et al. Clinicopathological characterisation of small (2 cm or less) proximal and distal gastric carcinomas in a Chinese population. Pathology. 2015;47(6):526-532.

83. Bae, J.M., \& Kim, E.H. Helicobacter pylori Infection and Risk of Gastric Cancer in Korea: A Quantitative Systematic Review. J. Prev. Med. Public Health. 2016;49(4):197-204.

84. Bakhti, S.Z., Latifi-Navid, S., Zahri, S., Bakhti, F.S., Hajavi, N., \& Yazd anBEd, A. Are Helicobacter pylori highly cytotoxic genotypes and cardia gastric adenocarcinoma linked? Lessons from Iran. Cancer Biomark. 2017;21(1):235-246.

85. Bakhti, S.Z., Latifi-Navid, S., Zahri, S., \& Yazdan BEd, A. Inverse association of Helicobacter pylori cagPAI genotypes with risk of cardia and non-cardia gastric adenocarcinoma. Cancer Med. 2019;8(10):4928-4937.

86. Chen, M.J., Wu, D.C., Ko, Y.C., \& Chiou, Y.Y. Personal history and family history as a predictor of gastric cardiac adenocarcinoma risk: a case-control study in Taiwan. Am $J$ Gastroenterol. 2004;99(7):1250-1257.

87. Coleman, H.G., Xie, S.H., \& Lagergren, J. The Epidemiology of Esophageal Adenocarcinoma. Gastroenterology. 2018;154(2):390-405

88. Murphy, G., Pfeiffer, R., Camargo, M.C., \& Rabkin, C.S. Meta-analysis shows that prevalence of Epstein-Barr virus-positive gastric cancer differs based on sex and anatomic location. Gastroenterology. 2009;137(3):824-833.

89. Osumi, H., et al. Risk stratification for lymph node metastasis using Epstein-Barr virus status in submucosal invasive (pT1) gastric cancer without lymphovascular invasion: a multicenter observational study. Gastric Cancer. 2019;22(6):1176-1182.

90. Kim, T.S., da Silva, E., Coit, D.G., \& Tang, L.H. Intratumoral Immune Response to Gastric Cancer Varies by Molecular and Histologic Subtype. Am J Surg Pathol. 2019;43(6):851-860. 
91. Sadato, D., et al. Potential prognostic impact of EBV RNA-seq reads in gastric cancer: A reanalysis of The Cancer Genome Atlas cohort. FEBS Open Bio. 2020;10(3):455-467.

92. Ding, G.C., et al. Human papillomavirus DNA and P16(INK4A) expression in concurrent esophageal and gastric cardia cancers. World J Gastroenterol. 2010;16(46):5901-5906.

93. Yan, R., et al. Microbiological evidences for gastric cardiac microflora dysbiosis inducing the progression of inflammation. J Gastroenterol Hepatol. 2019 Nov 29. doi: 10.1111/jgh.14946. [Epub ahead of print]

94. Global Burden of Disease Cancer Collaboration, et al. Global, Regional, and National Cancer Incidence, Mortality, Years of Life Lost, Years Lived With Disability, and Disability-Adjusted Life-Years for 29 Cancer Groups, 1990 to 2017: A Systematic Analysis for the Global Burden of Disease Study. JAMA Oncol. 2019 Sept 27. doi:10.1001/jamaoncol.2019.2996. [Epub ahead of print]

95. Liu, K., et al. Comparison between gastric and esophageal classification system among adenocarcinomas of esophagogastric junction according to AJCC 8th edition: a retrospective observational study from two high-volume institutions in China. Gastric Cancer. 2019;22(3): 506-517.

96. Fang, C., et al. Risk factors of early proximal gastric carcinoma in Chinese diagnosed using WHO criteria. J Dig Dis. 2015;16(6):327-336.

97. Feng, A.N., et al. Expression of SIRT1 in gastric cardiac cancer and its clinicopathologic significance. Int J Surg Pathol. 2011;19(6):743-750.

98. Özcan Ö, et al. Upregulation of SIRT1 gene in gastric adenocarcinoma. Turk J Gastroenterol. 2019;30(4):326-330.

99. Kang, M.H., et al. Estrogen-related receptor gamma functions as a tumor suppressor in gastric cancer. Nat. Commun. 2018;9(1):1920. doi: 10.1038/s41467-018-04244-2.

100. Cook, M.B., et al. Cigarette smoking and adenocarcinomas of the esophagus and esophagogastric junction: a pooled analysis from the international BEACON consortium. J. Natl. Cancer Inst. 2010;102(17):1344-1353.

101. Sjodahl, K., et al. Smoking and alcohol drinking in relation to risk of gastric cancer: a population-based, prospective cohort study. Int J Cancer. 2007;120(1):128-132.

102. Ji, B.T., et al. The influence of cigarette smoking, alcohol, and green tea consumption on the risk of carcinoma of the cardia and distal stomach in Shanghai, China. Cancer. 1996;77(12):2449-2457.

103. Agudo, A., et al. Inflammatory potential of the diet and risk of gastric cancer in the European Prospective Investigation into Cancer and Nutrition (EPIC) study. Am J Clin Nutr. 2018;107(4):607-616.

104. Song, M., et al. Family history of cancer in first-degree relatives and risk of gastric cancer and its precursors in a Western population. Gastric Cancer. 2018;21(5):729-737.

105. Mai, R., Cheng, Y., Huang, Y., \& Zhang, G. Esophageal squamous cell carcinoma and gastric cardia adenocarcinoma shared susceptibility locus in PLCE1: a meta-analysis. PLoS One. 2013;8(7):e69214. 
106. Wang, L.D., et al. Genome-wide association study of esophageal squamous cell carcinoma in Chinese subjects identifies susceptibility loci at PLCE1 and C20orf54. Nat. Genet. 2010;42(9):759-763.

107. Abnet, C.C., et al. A shared susceptibility locus in PLCE1 at 10q23 for gastric adenocarcinoma and esophageal squamous cell carcinoma. Nat. Genet. 2010;42(9):764-767.

108. Hu, N., et al. Genome-wide association study of gastric adenocarcinoma in Asia: a comparison of associations between cardia and non-cardia tumors. Gut. 2016;65(10):1611-1618.

109. Yuan, J., et al. Risk prediction for early-onset gastric carcinoma: a case-control study of polygenic gastric cancer in Han Chinese with hereditary background. Oncotarget. 2016;7(23): 33608-33615.

110. van Nistelrooij, A.M., Dinjens, W.N., Wagner, A., Spaander, M.C., van Lanschot, J.J., \& Wijnhoven, B.P. Hereditary Factors in Esophageal Adenocarcinoma. Gastrointest Tumors. 2014;1(2):93-98.

111. Chen, Y., et al. Body mass index and risk of gastric cancer: a meta-analysis of a population with more than ten million from 24 prospective studies. Cancer Epidemiol Biomark Prev. 2013;22(8):1395-1408.

112. O’Doherty, M.G., Freedman, N.D., Hollenbeck, A.R., Schatzkin, A., \& Abnet, C.C. A prospective cohort study of obesity and risk of esophageal and gastric adenocarcinoma in the NIH-AARP Diet and Health Study. Gut. 2012;61(9):1261-1268.

113. Sj€odahl, K., Jia, C., Vatten, L., Nilsen, T., Hveem, K., \& Lagergren, J. Body mass and physical activity and risk of gastric cancer in a population-based cohort study in Norway. Cancer Epidemiol. Biomarkers Prev. 2008;17(1):135-140.

114. Fan, J.H., Wang, J.B., Wang, S.M., Abnet, C.C., Qiao, Y.L., \& Taylor, P.R. Body mass index and risk of gastric cancer: A 30-year follow-up study in the Linxian general population trial cohort. Cancer Sci. 2017;108(8):1667-1672.

115. Yang, P., et al. Overweight, obesity and gastric cancer risk: results from a meta-analysis of cohort studies. Eur. J. Cancer. 2009;45(16):2867-2873.

116. McColl, K.E.L. What is causing the rising incidence of esophageal adenocarcinoma in the West and will it also happen in the East? J. Gastroenterol. 2019;54(8):669-673.

117. Carr JS, Zafar SF, Saba N, Khuri FR, El-Rayes BF. Risk factors for rising incidence of esophageal and gastric cardia adenocarcinoma. J. Gastrointest. Cancer. 2013;44(2):143-151.

118. Ye W, Chow WH, Lagergren J, Yin L, Nyrén O. Risk of adenocarcinomas of the esophagus and gastric cardia in patients with gastroesophageal reflux diseases and after antireflux surgery. Gastroenterology. 2001;121(6):1286-1293.

119. Palli D, Masala G, Del Giudice G et al. CagA+ Helicobacter pylori infection and gastric cancer risk in the EPIC-EURGAST study. Int. J. Cancer. 2007;121(4):928.

120. Derakhshan, M. H., et al. (2008). Combination of gastric atrophy, reflux symptoms and histological subtype indicates two distinct aetiologies of gastric cardia cancer. Gut. 2008;57(3):298-305. 
121. McColl KE. Cancer of the gastric cardia. Best Pract. Res. Clin. Gastroenterol. 2006;20(4):687-696.

122. Wang, X., et al. Residual embryonic cells as precursors of a Barrett's-like metaplasia. Cell. 2011;145(7):1023-1035.

123. Mukaisho, K., Nakayama, T., Hagiwara, T., Hattori, T., Sugihara, H. Two distinct etiologies of gastric cardia adenocarcinoma: interactions among $\mathrm{pH}$, Helicobacter pylori, and bile acids. Front. Microbiol. 2015;6:412.

124. Becker, L., Huang, Q., Mashimo, H. Immunostaining of Lgr5, an intestinal stem cell marker, in normal and premalignant human gastrointestinal tissue. ScientificWorldJournal. 2008;8:11681176.

125. Jiang, M., et al. Transitional basal cells at the squamous-columnar junction generate Barrett's esophagus. Nature. 2017;550(7677):529-533.

126. Cristescu R, et al. Molecular analysis of gastric cancer identifies subtypes associated with distinct clinical outcomes. Nat Med. 2015;21(5):449-456.

127. Deng, H.Y., et al. Tumor location is an independent prognostic factor of esophageal adenocarcinoma based on the eighth edition of TNM staging system in Chinese patients. Ann. Transl. Med. 2019;7(16):365.

128. Whitson, B.A., et al. Survival of patients with distal esophageal and gastric cardia tumors: a population-based analysis of gastroesophageal junction carcinomas. J. Thorac. Cardiovasc. Surg. 2010;139(1):43-48.

129. Gertler, R., Stein, H.J., Loos, M., Langer, R., Friess, H., \& Feith, M. How to classify adenocarcinomas of the esophagogastric junction: as esophageal or gastric cancer? Am. J. Surg. Pathol. 2011;35(10):1512-1522.

130.Huang, Q., et al. Gastric cardiac carcinomas involving the esophagus are more adequately staged as gastric cancers by the 7th edition of the American Joint Commission on Cancer Staging System. Mod. Pathol. 2011;24(1):138-146.

131. Suh, Y.S., et al. Should adenocarcinoma of the esophagogastric junction be classified as esophageal cancer? A comparative analysis according to the seventh AJCC TNM classification. Ann. Surg. 2012;255(5):908-915.

132. Sano, T., et al. Proposal of a new stage grouping of gastric cancer for TNM classification: International Gastric Cancer Association staging project. Gastric Cancer. 2017;20(2):217-225.

133. Liu, K., et al. Comparison between gastric and esophageal classification system among adenocarcinomas of esophagogastric junction according to AJCC 8th edition: a retrospective observational study from two high-volume institutions in China. Gastric Cancer. 2019;22(3):506-517.

134. Karstens, K.F., et al. Comparison of the 8th UICC staging system for esophageal and gastric cancers in Siewert type II junctional adenocarcinomas. Eur. J. Surg. Oncol. 2020;46(4 pt A):638643. 
135. Du M, et al. Tumor Budding and Other Risk Factors of Lymph Node Metastasis in Submucosal Early Gastric Carcinoma: A Multicenter Clinicopathologic Study in 621 Radical Gastrectomies of Chinese Patients. Am. J. Surg. Pathol. 2019;43(8):1074-1082.

136. Yamashita, H., et al. Results of a nation-wide retrospective study of lymphadenectomy for esophagogastric junction carcinoma. Gastric Cancer. 2017;20(Suppl 1):69-83.

137. Kurokawa Y, Hiki N, Yoshikawa T, et al. Mediastinal lymph node metastasis and recurrence in adenocarcinoma of the esophagogastric junction. Surgery. 2015;157(3):551-555. doi:10.1016/j.surg.2014.08.099

138. Kurokawa Y, Takeuchi H, Doki Y, et al. Mapping of Lymph Node Metastasis From Esophagogastric Junction Tumors: A Prospective Nationwide Multicenter Study [published online ahead of print, 2019 Aug 8]. Ann Surg. 2019;10.1097/SLA.0000000000003499. doi:10.1097/SLA.0000000000003499.

139. Sasako, M., et al. Left thoracoabdominal approach versus abdominal-transhiatal approach for gastric cancer of the cardia or subcardia: a randomised controlled trial. Lancet Oncol. 2006;7(8):644-651.

140. Japanese gastric cancer treatment guidelines 2014 (ver. 4). Japanese Gastric Cancer Association. Gastric Cancer. 2017;20(1):1-19.

141. Wang, F.H., et al. The Chinese Society of Clinical Oncology (CSCO): clinical guidelines for the diagnosis and treatment of gastric cancer. Cancer Commun. (Lond.). 2019;39(1):10.

142. Karanicolas PJ, Graham D, Gönen M, Strong VE, Brennan MF, Coit DG. Quality of life after gastrectomy for adenocarcinoma: a prospective cohort study. Ann Surg. 2013;257(6):10391046.

143. Yura M, et al. Is surgery alone sufficient for treating T1 gastric cancer with extensive lymph node metastases? Gastric Cancer. 2020;23(2):349-355.

This article is protected by copyright. All rights reserved. 


\section{FIGURE LEGENDS}

Figure 1. Schematic drawing of the gastric cardia that is $3 \mathrm{~cm}$ below and $2 \mathrm{~cm}$ above the gastroesophageal junction (GEJ) at the angle of His.

Figure 2. Gastric cardiac mucosa with mucous and mucoxyntic glands distal to the gastroesophageal junction (GEJ). Immediately distal to the GEJ line was pure mucous glands. Once parietal cells (black arrows in the left lower panel) are admixed with mucous glands, the mucoxyntic mucosa is formed. The square areas lined with solid and dashed lines are enlarged in the left and right lower panels to illustrate detailed cytomorphology. Note a small cluster of superficial esophageal cardiac mucous glands underneath squamous epithelium on the left of the GEJ line (Hematoxylin-eosin stains).

Figure 3. Cardiac mucosa exhibits a continuity of growth from the proximal gastric cardia through the gastroesophageal junction into the distal esophagus underneath squamous epithelium (A). Note mucous columnar epithelium-lined cardiac gland ducts (arrows in A), one with goblet cell/intestinal metaplasia (arrow in B), running upwards through the squamous epithelium. In C, a centrally ulcerated tumor was identified at upper endoscopy in the gastric cardia with an estimated size of $1.5 \mathrm{~cm}$ and about $1.0 \mathrm{~cm}$ from the gastroesophageal junction in a 73-year old man with a 6-month history of gastroesophageal reflux disease. The biopsy of this tumor was diagnosed as tubular adenocarcinoma with distal esophageal extension (D). There is no evidence of Barrett's esophagus (Hematoxylin-eosin stains in A, B, and C).

Figure 4. Two-etiology hypothesis for tumorigenesis mechanisms of gastric cardiac carcinoma. In low-risk regions, obesity-reflux disease damages cardiac glands, leading to marked glandular atrophy (A). In contrast, in high-risk regions, Hp infection-associated chronic inflammation is dominant in the cardia without marked atrophy (B). Both key risk factors may further induce intestinal metaplasia, dysplasia (C), and adenocarcinoma (D) (All hematoxylin-eosin stains). 
Table 1. Comparison of Pathologic Features between Gastric Cardiac Cancer and Esophageal Adenocarcinoma

\begin{tabular}{|c|c|c|c|}
\hline Pathology & $\begin{array}{l}\text { Gastric } \\
\text { Cancer } \\
(\%)^{*}\end{array}$ & $\begin{array}{l}\text { Esophageal } \\
\text { Adenocarcinoma } \\
(\%)\end{array}$ & Reference \\
\hline Epicenter location & $\begin{array}{l}3 \mathrm{~cm} \text { below and } 2 \mathrm{~cm} \\
\text { above the GEJ line }\end{array}$ & $\begin{array}{l}>2 \mathrm{~cm} \text { above the GEJ } \\
\text { line }\end{array}$ & 1,2 \\
\hline $\begin{array}{l}\text { Prevalence of intestinal } \\
\text { metaplasia in adjacent mucosa }\end{array}$ & Low & High & $17-19$ \\
\hline $\begin{array}{l}\text { Long-segment } \\
\text { esophagus }\end{array}$ & Absent & Present & 35 \\
\hline \multicolumn{4}{|l|}{ Adenocarcinoma (\%) } \\
\hline Tubular/papillary & $77-87.3$ & 100 & $28,35,38,54,82$ \\
\hline Mucinous & $1.4-21$ & 0 & $28,35,54,82$ \\
\hline Poorly cohesive & 2.2 & 0 & $35,54,82$ \\
\hline Mixed & 4.2 & 0 & 35,54 \\
\hline \multicolumn{4}{|l|}{ Uncommon adenocarcinoma } \\
\hline Micropapillary & $0.8-2.2$ & 0 & $28,35,38,54$ \\
\hline Hepatoid & $10-20$ & 0 & 39,40 \\
\hline EBV-related & $0.8-15$ & 0 & 30,54 \\
\hline Pancreatic acinar-like & $4.6-7$ & 0 & $30,32,38$ \\
\hline \multicolumn{4}{|l|}{ Rare carcinoma } \\
\hline Adenosquamous & $0.4-16$ & 0 & $34,35,38,54$ \\
\hline Neuroendocrine & $0.8-2$ & 0 & $35,38,54$ \\
\hline Carcinosarcoma, melanoma, & Rare & 0 & $38,42,43$ \\
\hline
\end{tabular}

This article is protected by copyright. All rights reserved. 
choriocarcinoma

Note: *: The marked variations in the percentage of cases in the gastric cardiac cancer group are due to different types (early versus advanced gastric cardiac cancer resections) and sizes of the study specimens cited in various reports.

Table 2. Comparison of Epidemiology between Gastric Cardiac Carcinoma and Esophageal Adenocarcinoma

\begin{tabular}{|c|c|c|c|}
\hline Epidemiology & Gastric Cardiac Cancer & $\begin{array}{l}\text { Esophageal } \\
\text { Adenocarcinoma }\end{array}$ & Reference \\
\hline High-risk region & $\begin{array}{l}\text { China, Central Asian } \\
\text { Countries }\end{array}$ & $\begin{array}{lr}\text { Most } & \text { European, } \\
\text { North } & \text { America, } \\
\text { Oceania } & \end{array}$ & 65 \\
\hline Low-risk region & $\begin{array}{l}\text { Japan, Korea, European, } \\
\text { America, Oceania }\end{array}$ & $\begin{array}{l}\text { China, Japan, Korea, } \\
\text { Asia, Africa }\end{array}$ & $\begin{array}{l}65,80 \\
65,80\end{array}$ \\
\hline Male:Female Ratio & $3: 1$ & Up to $9: 1$ & $54,65,79$ \\
\hline Average age (year) & $60 s$ & $70 \mathrm{~s}$ & 4,95,96 \\
\hline \multicolumn{4}{|l|}{ Risk factors } \\
\hline H. pylori & High-risk & Protective & 79 \\
\hline Epstein-Barre & High-risk & Not reported & 36, 48, 88, 89. \\
\hline \multicolumn{4}{|l|}{ Virus } \\
\hline Smoking & High-risk & High-risk & 101, 102 \\
\hline Diet & Uncertain & Meat, animal fat & 79, 104 \\
\hline Family cancer history & Esophageal/gastric cancer & $7 \%$ & $41,87,104-110$ \\
\hline Obesity & Low-risk & High-risk & $111,112,115,116$ \\
\hline
\end{tabular}

This article is protected by copyright. All rights reserved. 
Table 3. Options for GCC Tumor Resections

\begin{tabular}{llll}
\hline \multicolumn{1}{c}{ Tumor Stage (pT) } & $\begin{array}{l}\text { Endoscopic } \\
\text { Resection }\end{array}$ & Surgical Resection & Reference \\
\hline pT1a & Recommended & No & $54,139,140$ \\
pT1b & & & \\
Well-moderate differentiation & Recommended & No & $54,139,140$ \\
Size $<3 c m$ & Recommended & No & $54,142,143$ \\
Rare carcinomas & Recommended & No & 54 \\
Poor differentiation & No & Recommended & $54,139,140$ \\
Lymphovascular invasion & No & Recommended & $54,139,140$ \\
Tumor budding & No & Recommended & 136 \\
pT2 & No & Recommended & 139,140 \\
& \multicolumn{2}{c}{ With nodal }
\end{tabular}

This article is protected by copyright. All rights reserved. 


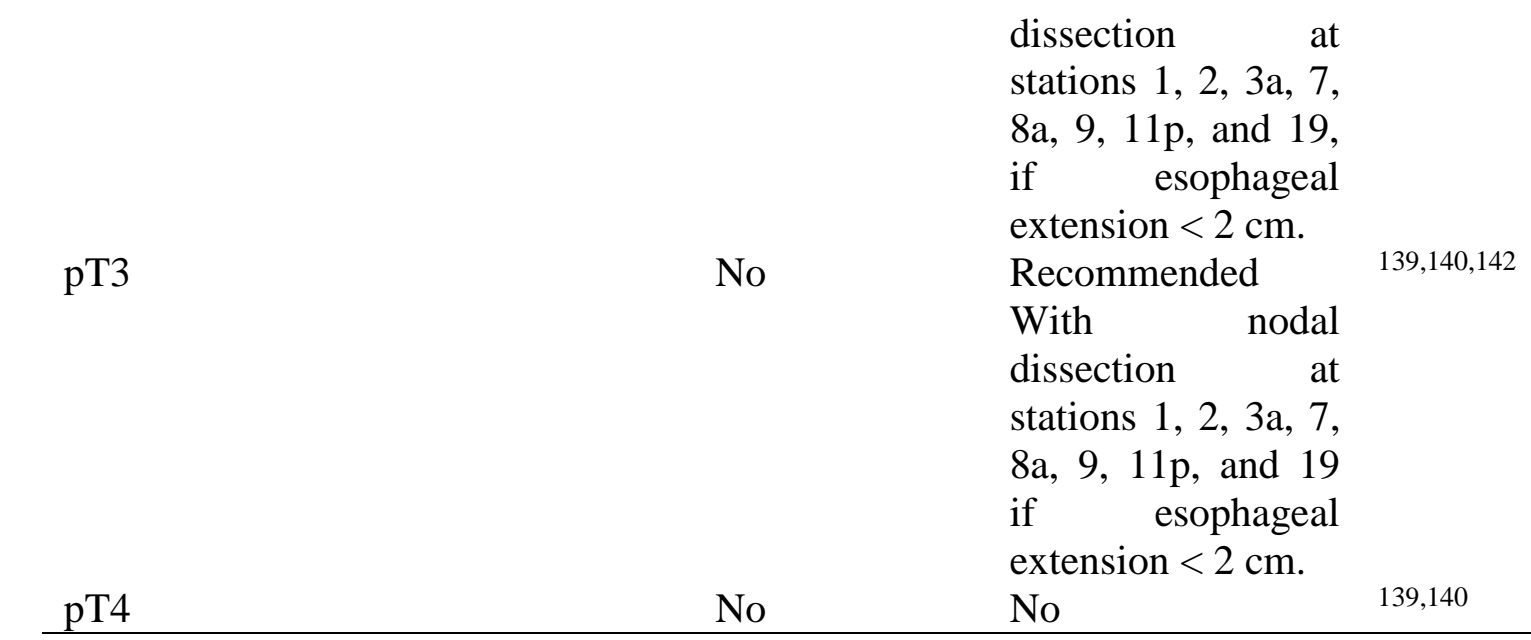

Note: for pT1 early GCC with nodal metastasis, adjuvant chemotherapy after surgical resection is recommended. ${ }^{142}$ 


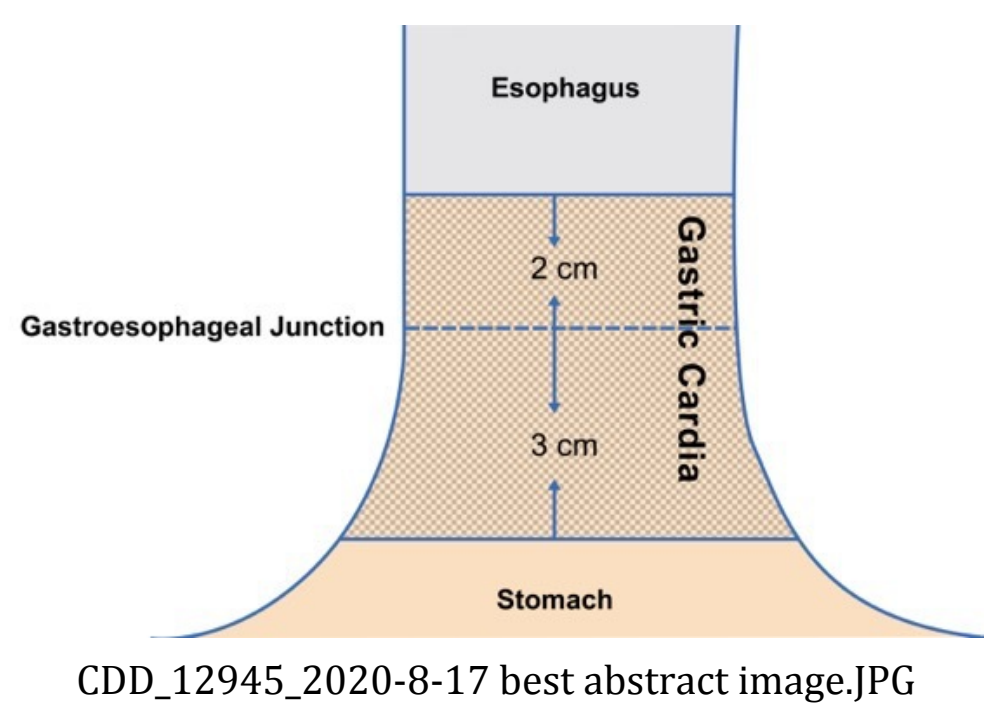

This article is protected by copyright. All rights reserved. 


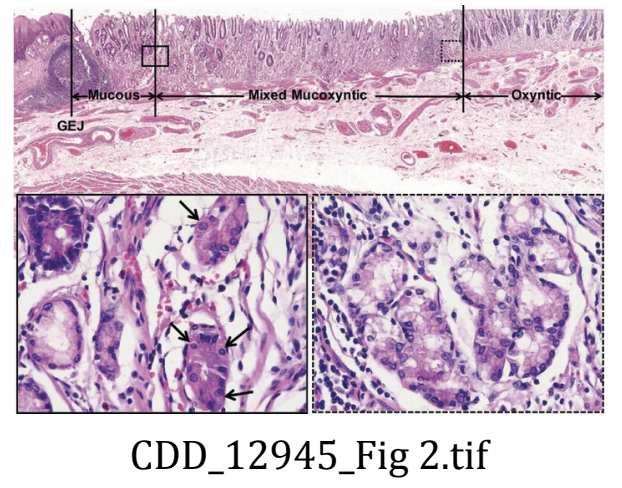

This article is protected by copyright. All rights reserved. 


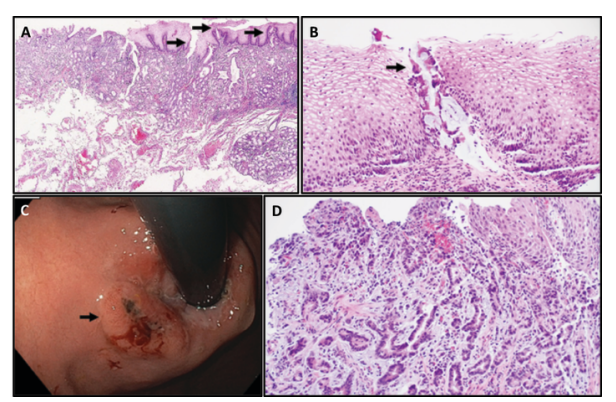

CDD_12945_Fig 3.tif

This article is protected by copyright. All rights reserved. 


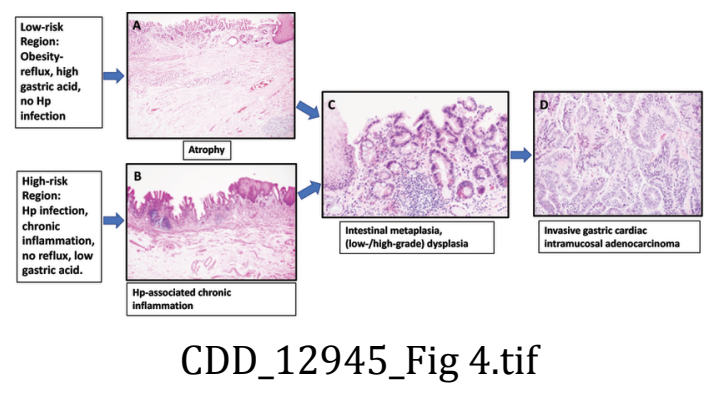

This article is protected by copyright. All rights reserved. 


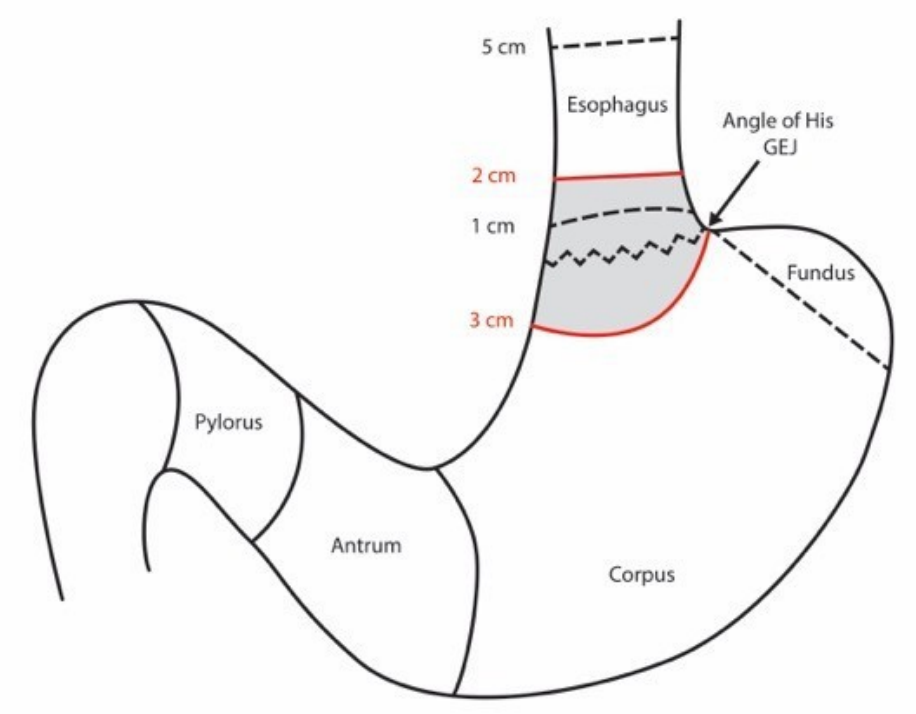

CDD_12945_Figure 1.jpg

This article is protected by copyright. All rights reserved. 


\section{Graphic Abstract Text}

Gastric cardiac carcinoma arises in cardiac mucosa and shows epidemiologic, pathologic, genomic, and prognostic features more like those of gastric carcinoma than those of esophageal carcinoma. This cancer is epicentered $2 \mathrm{~cm}$ above and $3 \mathrm{~cm}$ below the gastroesophageal junction without the evidence of long-segment Barrett's esophagus. Endoscopic therapy is preferred for early gastric cardiac carcinoma because of very low risk of nodal metastasis. 


\section{Unraveling the Identity of Gastric Cardiac Cancer}

Qin Huang, ${ }^{1,2 *}$ Matthew Read, ${ }^{3}$ Jason S. Gold, ${ }^{4}$ Xiaoping Zou ${ }^{5}$

${ }^{1}$ Department of Pathology of Nanjing Drum Tower Hospital, Nanjing, China

${ }^{2}$ Department of Pathology and Laboratory Medicine, Veterans Affairs Boston Healthcare System, Harvard Medical School/Brigham and Women’s Hospital, Boston, USA.

${ }^{3}$ Department of Surgery, St Vincent's Hospital, Melbourne, Australia.

${ }^{4}$ Department of Surgery, Veterans Affairs Boston Healthcare System, Harvard Medical School/Brigham and Women's Hospital, Boston, USA.

${ }^{5}$ Department of Gastroenterology of Nanjing Drum Tower Hospital affiliated to Nanjing University Medical School, Nanjing, China

\section{*Corresponding author:}

Qin Huang, Department of Pathology and Laboratory Medicine, Veterans Affairs Boston Healthcare System and Harvard Medical School, 1400 VFW Parkway, West Roxbury, MA 02132, U.S.A.

Email: qin.huang@va.gov; qinhuang0122@gmail.com

Office Phone: 857-203-5020.

FAX: 857-203-5623. 


\section{University Library}

\section{- M M I E E R VA A gateway to Melbourne's research publications}

Minerva Access is the Institutional Repository of The University of Melbourne

Author/s:

Huang, Q;Read, M;Gold, JS;Zou, XP

Title:

Unraveling the identity of gastric cardiac cancer.

Date:

2020-12

Citation:

Huang, Q., Read, M., Gold, J. S. \& Zou, X. P. (2020). Unraveling the identity of gastric cardiac cancer.. J Dig Dis, 21 (12), pp.674-686. https://doi.org/10.1111/1751-2980.12945.

Persistent Link:

http://hdl.handle.net/11343/276540 